\title{
Assédio moral laboral: planejamento estratégico para a ruptura do ciclo de violência a partir da enfermagem do trabalho.
}

Israel Coutinho Sampaio Lima ${ }^{1}$, Antonio Rodrigues Ferreira Junior ${ }^{2}$, Dayze Djanira Furtado de Galiza ${ }^{3}$, José Jackson Coelho Sampaio ${ }^{4}$, Iolanda Bezerra dos Santos Brandão ${ }^{5}$

\footnotetext{
${ }^{1}$ Enfermeiro. Doutorando em Saúde Coletiva pela Universidade Estadual do Ceará, Fortaleza, Ceará, Brasil. ORCID: 0000-0002-19296142

2 Enfermeiro, Doutor em Saúde Coletiva, Universidade Estadual de Campinas, Docente da Graduação em Enfermagem e da Pósgraduação em Saúde Coletiva da Universidade Estadual do Ceará, Fortaleza, Ceará, Brasil. ORCID: 0000-0002-9483-8060

${ }^{3}$ Enfermeira, Doutoranda em Saúde Coletiva pela Universidade Estadual do Ceará, Fortaleza, Ceará, Brasil. ORCID: 0000-0001-92370372

${ }^{4}$ Psiquiatra, Doutor em Medicina Preventiva, Universidade de São Paulo, Docente do Programa de Pós-Graduação em Saúde Coletiva da Universidade Estadual do Ceará, Fortaleza, Ceará, Brasil. ORCID: 0000-0003-4364-524X

${ }^{5}$ Psicóloga, Doutora em Psicologia, Pontifícia Universidade Católica de São Paulo, Docente da Graduação em Psicologia Centro Universitário Euro Americano, Brasília, Distrito Federal, Brasil. ORCID: 0000-0002-8816-694X
}

\section{Información del artículo}

Recibido: 26-08-2020

Aceptado: 02-03-2021

DOI:

10.15517/revenf.v0i41.43615

\section{Correspondencia}

Israel Coutinho Sampaio

Lima

Universidade Estadual do

Ceará, Fortaleza, Ceará,

Brasil.

Email:

isracoutinho@hotmail.com

\section{RESUMO}

Este ensaio objetivou refletir sobre a dinâmica do assédio moral laboral e a função da Enfermagem do Trabalho no planejamento estratégico para a ruptura deste ciclo de violência. Trata-se de um ensaio teórico, que tem como base as obras de Margarida Maria Silveira Barreto, Lis Andreia Soboll e colaboradores, pesquisadoras importantes sobre o assédio moral no trabalho, no cenário brasileiro. As discussões denotam que a escolha de um dado modelo econômico, por um país, tem forte influência sobre a saúde e a segurança ocupacional dos empregados, devido a situações de hostilidade, constrangimento, humilhação, intimidação e ofensas pelo agressororganização, que podem resultar em vários danos psicossociais: menos-valia, insatisfação, indignação, desânimo, ansiedade, depressão, isolamento social, síndrome do pânico, tensão muscular, suicídio, entre outros. Diante de tal contexto, apesar do enfermeiro do trabalho desenvolver ações de diagnóstico situacional de segurança ocupacional dos serviços, elaborando, executando e avaliando, planos estratégicos em ações de prevenção, promoção, proteção e de recuperação da saúde dos trabalhadores, não há meios sistematizados que o apóiem. Para tanto, propõe-se a utilização do planejamento estratégico para o enfrentamento do ciclo de violência. As etapas de investigação ajudam a promover espaços de diálogos entre empregados e gestores, em prol da luta contra o assédio moral. 
Palavras-chave: Enfermagem-do-Trabalho; Saúde-do-Trabalhador; Violênciano-Trabalho.

\section{RESUMEN}

\section{Acoso moral laboral: planificación estratégica para romper el ciclo de violencia, a partir de la enfermería ocupacional}

Este ensayo tuvo como objetivo reflexionar sobre la dinámica del acoso laboral y el papel de la enfermería ocupacional en la planificación estratégica para romper este ciclo de violencia. Este es un ensayo teórico, basado en los trabajos de Margarida Maria Silveira Barreto, Lis Andreia Soboll y colaboradores, quienes son consideradas importantes investigadoras sobre el acoso laboral, en el escenario brasileño. Las discusiones muestran que la elección de un determinado modelo económico por parte de un país tiene una fuerte influencia en la salud y seguridad ocupacional de los empleados, debido a situaciones de hostilidad, vergüenza, humillación, intimidación y ofensas por parte de la organización agresora, que pueden resultar en problemas psicosociales y daños, tales como pérdida de valor, insatisfacción, indignación, desánimo, ansiedad, depresión, aislamiento social, síndrome de pánico, tensión muscular, suicidio, entre otros. Ante tal contexto, a pesar de que la persona enfermera ocupacional desarrolla acciones de diagnóstico situacional de seguridad ocupacional de los servicios - al elaborar, ejecutar y evaluar planes estratégicos en acciones de prevención, promoción, protección y recuperación de la salud de las personas trabajadoras- no existen medios sistematizados para ayudarla en estas acciones. Para ello, se propone utilizar la planificación estratégica contra el ciclo de la violencia, que posee etapas de investigación que ayudaron a promover espacios de diálogo entre personas empleadas y directivas, a favor de la lucha contra el acoso moral.

Palabras clave: Enfermería-del-Trabajo; Salud-Laboral; Violencia-Laboral.

\section{ABSTRACT}

\section{Workplace bullying: strategic planning to break the cycle of violence based on occupational nursing.}

This essay aimed to reflect on the dynamics of workplace bullying and the role of occupational nursing in the strategic planning to break this cycle of violence. This is a theoretical essay based on the works of Margarida Maria Silveira Barreto, Lis Andreia Soboll, and some other collaborators considered important researchers in the field of bullying at work in the Brazilian scenario. Discussions show that a country's decision for a given economic model has a strong impact on the occupational health and safety of employees due to its influence on 
situations of hostility, embarrassment, humiliation, intimidation and offenses by the aggressor-organization. This can result in psychosocial damage such as loss of value, dissatisfaction, indignation, discouragement, anxiety, depression, social isolation, panic syndrome, muscle tension, suicide, among others. Despite the fact that occupational nurses develop actions of situational diagnosis of occupational safety of the services in these contexts-while also elaborating, executing and evaluating action plans for the prevention, promotion, protection, and recovery of the workers' health-there are no systematized means to assist nurses in this. As a result, it is proposed to use strategic planning against the cycle of violence, which has research stages that helped promote spaces for dialogue between employees and managers, in favor of the fight against moral harassment.

Keywords: Occupational-Health-Nursing; Occupational-Health; WorkplaceViolence.

\section{INTRODUÇÃO}

Este ensaio teórico parte da compreensão de que o desconhecimento dos elementos que caracterizam a dinâmica laboral do assédio moral pelo enfermeiro do trabalho inviabiliza a elaboração de condutas que auxiliem este profissional a identificar e a desenvolver ações para a quebra deste ciclo de violência. Logo, problematizar este assunto, sob uma perspectiva teórica e crítica, se faz importante e relevante, não só para a Enfermagem do Trabalho, como também para todos os demais membros da equipe multiprofissional que compõem os Serviços de Medicina e Segurança Ocupacional, além de gestores e trabalhadores dos diversos campos de atuação, uma vez que não existem políticas públicas específicas de combate ao assédio moral no trabalho que auxiliem na identificação e na ruptura deste tipo de violência.

Para tanto, é preciso que a problematização sobre o assédio moral no ambiente laboral tenha início a partir dos valores que o capital vem empregando na sociedade e da influência deste na vida dos trabalhadores $^{1}$. Pode-se, então, inferir que uma parte da sociedade vive sobre o maniqueísmo gerado pelo capitalismo, por meio das políticas liberais de mercado que promovem a divisão social do trabalho, que, por sua vez, privilegia de maneira distinta e desigual os sujeitos, conforme a classe social, em relação aos bens produzidos.

Nessa perspectiva, o capitalismo intensifica a exploração da força de trabalho ${ }^{2}$, por meio da flexibilidade sobre as formas de vínculos, menor tempo para as necessidades fisiológicas, rigidez sobre as regras impostas ao cargo e maior tempo dedicado à empresa ${ }^{3}$.

Neste tipo de lógica de trabalho, é comum que exista assédio moral, tendo origem na diversidade das relações de poder entre trabalhadores e/ou das organizações sobre eles em ambiente público ou privado ${ }^{4}$. Logo, o assédio moral laboral se dá como um risco não visível, durante a jornada de trabalho, diante de determinados atos, comportamentos e situações constrangedoras que se dão de forma repetitiva e duradoura ${ }^{5-10}$.

Nesse contexto, o enfermeiro do trabalho se depara em seu cotidiano laboral com várias situações de agravo à saúde, sendo o assédio moral uma delas, que inferem diretamente na saúde individual e 
coletiva dos trabalhadores sobre sua responsabilidade. Em sua prática diária, este profissional desenvolve ações de diagnóstico situacional de segurança e periculosidade da empresa, elaborando, executando e avaliando, planos estratégicos em ações de promoção, proteção e de recuperação da saúde dos trabalhadores, sobre tudo na prevenção de doenças relacionadas ao trabalho, seja ela biológica, física, química ou psicossocial $^{4}$. Buscando reconhecer este cenário de forma sistematizada, que foi elencada as seguintes questões: Como se dá a dinâmica do assédio moral no trabalho? De que forma o enfermeiro do trabalho pode identificar relações de poder caracterizadas como assédio moral no trabalho? Quais condutas deverão ser elaboradas para que esse ciclo de violência seja quebrado?

Neste ensaio, objetivou-se refletir sobre a dinâmica do assédio moral laboral e a função da Enfermagem do Trabalho no planejamento estratégico para a ruptura deste ciclo de violência. A partir disso, serão elencadas condutas no que diz respeito à ação do enfermeiro do trabalho no enfrentamento do fenômeno estudado.

\section{DESENVOLVIMENTO}

\section{A dinâmica do assédio moral no trabalho}

É importante que a compreensão sobre a dinâmica do assédio moral laboral seja apresentada de forma que trabalhadores em geral, gestores e sociedade possam visualizar o desenvolvimento do fenômeno a partir de uma cadeia causal, apesar de sua subjetividade. Para isso, idealizou-se a (Figura 1) com base na reflexão e análise feita sobre a temática ${ }^{4-16}$.

Como observado na Figura 1, a escolha de um dado modelo econômico adotado por um país influenciará diretamente nas condições de trabalho dos sujeitos. Sob o olhar histórico, o Brasil passa a sofrer de forma mais brusca com as mudanças sobre os processos de trabalho a partir do avanço industrial na década de
1970. Neste mesmo período ocorre uma crise mundial do capital, culminando em 1990 com a divisão do trabalho em âmbito internacional, a fim de otimizar a cadeia produtiva. Isso agravou a exploração da força laboral, por meio das formas de organização ocupacional, da produção e da acumulação de riquezas s,5-7,15. $^{\text {. }}$

É a partir dessas mudanças diante da necessidade do capital que se verifica a influência do modelo econômico sobre a organização do trabalho, o qual passa a ser compreendido como um sistema composto por três elementos: a divisão do trabalho, a hierarquização do sistema e as relações de poder. Impõe-se de forma clara uma divisão social entre os trabalhadores e estes passam a se relacionar de forma competitiva, usufruindo de forma distinta dos privilégios, conforme o nível hierárquico ou classe social pertencente $e^{1,2,17}$.

É neste contexto que o neoliberalismo vem tomando forma, saindo da idealização para o campo operacional no qual as falhas geradas por outro tipo de modelo econômico justificam sua implementação, pois, para seus defensores, tudo se legitima como fundamental para que ocorra o desenvolvimento industrial e tecnológico de um país, ocasionando o desemprego, diante da desvalorização da vida ligada à ocupação, devido a incorporação de novas tecnológicas sem a regulação do Estado 6,7.

Desta forma, compreende-se que a influência do modelo econômico como visto na figura 1, causará a precarização do trabalho por meio dos baixos salários, da diminuição da proteção trabalhista, da intensificação do trabalho, da informalidade e da flexibilização da legislação trabalhista de cada país. É devido à flexibilização do trabalho, amparada pelo critério de redução de direitos dos trabalhadores, que novas formas de precarização do trabalho vêm sendo implementadas pelas organizações públicas ou privadas, como forma de gestão institucional ${ }^{2,7}$. 


\section{Figura 1}

Dinâmica do assédio moral laboral- Fortaleza, CE, Brasil, 2020.

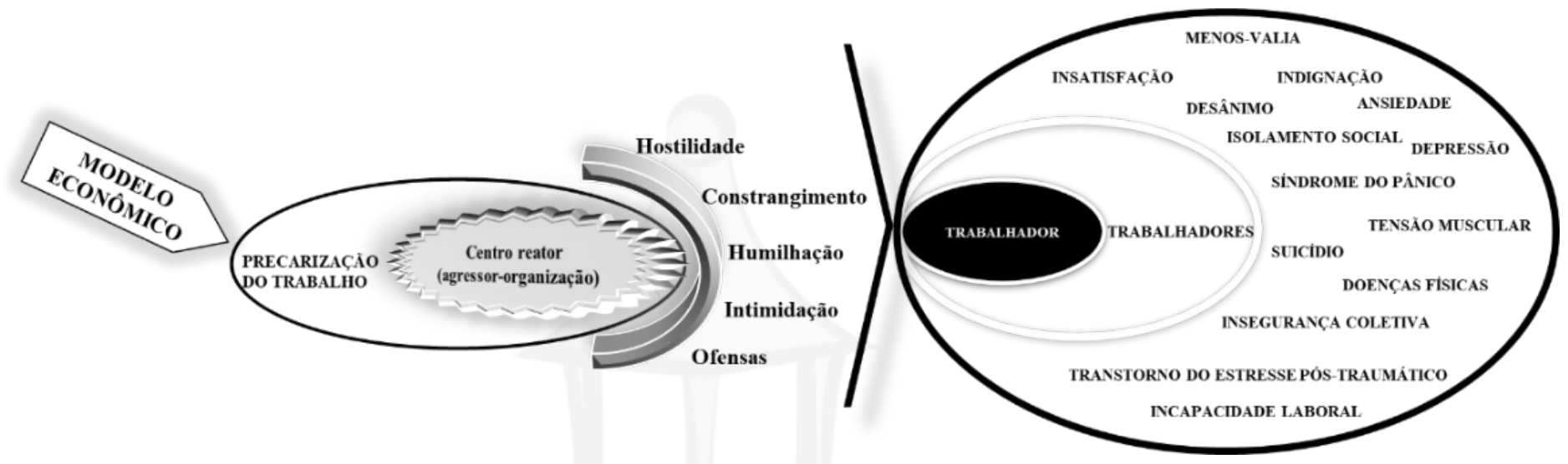

Fonte: Elaboração própria.

Além disso, historicamente, esse tipo de processo tende a precarizar o trabalho por meio do desemprego, da redução dos direitos sociais, da flexibilização dos contratos de trabalho, via terceirização ou qualquer outra forma não regular do vínculo trabalhístico. Porém os danos causados aos profissionais comumente são tidos como de menos valia diante das necessidades do modelo econômico ${ }^{6,10,16}$.

Nesse cenário, o isolamento do profissional é algo desejado pelo mercado de tal forma que não seja possível criar espaços de conciliação, troca de experiências ou camaradagem, pois o objetivo de sua existência é a produção. Essa perspectiva torna o trabalhador um produto do capital (máquina), o qual foi domado, amordaçado e alienado. O que é contraditório, pois as mesmas organizações impõem na contramão da dominação dos processos de trabalho a busca pela excelência, destreza, desenvolvimento de habilidades e a participação ${ }^{1,2,6-}$ 10,17

Esse contexto pode tornar caótica a vida do trabalhador diante do que é possível e impossível naquela cultura institucional. Desta forma, as organizações e os trabalhadores que sofrem as consequências da precarização do trabalho vivem dentro de um centro reator. São estes os responsáveis pela prática ou perpetuação do assédio moral, a depender das relações de poder de uns sobre outros, como apresentado na (figura 1).

A dinâmica do centro reator ocorre pelo controle gerado sobre o processo de trabalho, fruto do modelo Taylorista, o qual fragmenta a produção e promove internamente a humilhação entre os trabalhadores, impossibilitando a estes a aquisição sobre o conhecimento total da cadeia produtiva ${ }^{7}$. É a partir desta dominação que o controle exercido sobre a subjetividade dos trabalhadores se perpetua de forma velada ${ }^{9,18}$.

Compreende-se que a composição do centro reator é constituída por meio da relação agressororganização, sendo, portanto, ações ou comportamentos indistintos, pois ambos estão diretamente ligados pela cultura do serviço ${ }^{7}$. Relação esta que favorece novas configurações de violência ligadas à dominação e à servidão dos trabalhadores ${ }^{6-}$ 10
Outro elemento posto, característico do centro reator, é o poder, em forma de ações que emanam deste para um dado profissional e ao grupo de 
colaboradores que presenciam o assédio moral, como representado na figura 1 , por meio de constrangimento, hostilidade, humilhações, ofensas e intimidação. Neste momento, é preciso que os profissionais que sofrem a agressão não internalizem ou se culpabilizem por uma deficiência produzida pelo superior ou pela organização ${ }^{10}$.

Comumente, a manifestação do assédio moral de forma sutil se dá pela retirada dos meios de trabalho, pelo não favorecimento de informações, cobrança excessiva ou pelo não fornecimento de condições adequadas para o desempenho das funções para aquele cargo. É diante da deficiência causada pela gestão ao trabalhador que o agressor se volta para a vítima, caracterizando-a como incompetente, preguiçosa ou improdutiva ${ }^{6,7,18}$. Neste ponto, a intencionalidade do ato pode estar clara ou velada, contudo os sujeitos e as organizações sempre serão responsáveis pelos atos cometidos ${ }^{5,10}$.

A violência psicológica gerada pelo assédio moral tende a causar o adoecimento destes trabalhadores, como visto na figura 1, por provocarem danos psicossociais reparáveis e irreparáveis, tais como: menos-valia, insatisfação, indignação, desânimo, ansiedade, depressão, isolamento social, síndrome do pânico, tensão muscular, suicídio, doenças físicas, insegurança coletiva dos trabalhadores, transtornos do estresse pós-traumático e incapacidade laboral $4,5,7,10,16,19,20$.

Tais consequências mostram como a prática abusiva gerada pelo assédio moral pode prejudicar a saúde do trabalhador, sendo, portanto, considerado crime de abuso de autoridade que busca preservar a dignidade e a liberdade individual conforme art. 4 da Lei no 4.898, de 1965, que versa sobre o Direito de Representação e o processo de Responsabilidade Administrativa Civil e Penal, nos casos de abuso de autoridade, diante da submissão da pessoa ao constrangimento ${ }^{17,21}$. \\ WWW.revenf.UCr.ac. Cr
Rica
De todo modo, as empresas devem desenvolver o
acompanhamento e a avaliação permanente sobre
as condições ocupacionais não só da estrutura física,
mas sobre a subjetividade inerente as relações
humanas. Sendo fundamental verificar situações
conflitantes, emitir relatórios organizacionais, além
de estratégias psicossociais, que previnam tais riscos,
a fim de extinguir o ciclo de violência causado pelo
assédio moral'.
Para tanto, os serviços precisam buscar assessorias
ou incorporar em seu quadro de funcionários
profissionais devidamente qualificados para tal
abordagem. Propomos que o enfermeiro do trabalho
seja incluído nas equipes multiprofissionais de
Segurança e Medicina do Trabalho, exatamente pela
característica do seu fazer, uma vez que este possui
habilidades gerenciais e psicossociais ligadas à
produção de saúde. Ele, dentro das ações nesta área,
buscará desenvolver planos estratégicos que tornem
as organizações mais saudáveis, integrando os
trabalhadores em prol do crescimento coletivo
organizacional, de maneira prática e reflexiva sobre o
desenvolvimento dos processos de trabalho, não
mais individual. Promovendo, assim, medidas que
coíbam de forma efetiva a prática do assédio moral
laboral22. \\ WWW.revenf. UCr.aC.Cr
De todo modo, as empresas devem desenvolver o
acompanhamento e a avaliação permanente sobre
as condições ocupacionais não só da estrutura física,
mas sobre a subjetividade inerente as relações
humanas. Sendo fundamental verificar situações
conflitantes, emitir relatórios organizacionais, além
de estratégias psicossociais, que previnam tais riscos,
a fim de extinguir o ciclo de violência causado pelo
assédio moral?
Para tanto, os serviços precisam buscar assessorias
ou incorporar em seu quadro de funcionários
profissionais devidamente qualificados para tal
abordagem. Propomos que o enfermeiro do trabalho
seja incluído nas equipes multiprofissionais de
Segurança e Medicina do Trabalho, exatamente pela
característica do seu fazer, uma vez que este possui
habilidades gerenciais e psicossociais ligadas à
produção de saúde. Ele, dentro das ações nesta área,
buscará desenvolver planos estratégicos que tornem
as organizações mais saudáveis, integrando os
trabalhadores em prol do crescimento coletivo
organizacional, de maneira prática e reflexiva sobre o
desenvolvimento dos processos de trabalho, não
mais individual. Promovendo, assim, medidas que
coíbam de forma efetiva a prática do assédio moral
laboral22. \\ WWW.revenf.UCr.aC.Cr
De todo modo, as empresas devem desenvolver o
acompanhamento e a avaliação permanente sobre
as condições ocupacionais não só da estrutura física,
mas sobre a subjetividade inerente as relações
humanas. Sendo fundamental verificar situações
conflitantes, emitir relatórios organizacionais, além
de estratégias psicossociais, que previnam tais riscos,
a fim de extinguir o ciclo de violência causado pelo
assédio moral?.
Para tanto, os serviços precisam buscar assessorias
ou incorporar em seu quadro de funcionários
profissionais devidamente qualificados para tal
abordagem. Propomos que o enfermeiro do trabalho
seja incluído nas equipes multiprofissionais de
Segurança e Medicina do Trabalho, exatamente pela
característica do seu fazer, uma vez que este possui
habilidades gerenciais e psicossociais ligadas à
produção de saúde. Ele, dentro das ações nesta área,
buscará desenvolver planos estratégicos que tornem
as organizações mais saudáveis, integrando os
trabalhadores em prol do crescimento coletivo
organizacional, de maneira prática e reflexiva sobre o
desenvolvimento dos processos de trabalho, não
mais individual. Promovendo, assim, medidas que
coíbam de forma efetiva a prática do assédio moral
laboral22. \\ WWW.revenf. UCr.aC.Cr
De todo modo, as empresas devem desenvolver o
acompanhamento e a avaliação permanente sobre
as condições ocupacionais não só da estrutura física,
mas sobre a subjetividade inerente as relações
humanas. Sendo fundamental verificar situações
conflitantes, emitir relatórios organizacionais, além
de estratégias psicossociais, que previnam tais riscos,
a fim de extinguir o ciclo de violência causado pelo
assédio moral?
Para tanto, os serviços precisam buscar assessorias
ou incorporar em seu quadro de funcionários
profissionais devidamente qualificados para tal
abordagem. Propomos que o enfermeiro do trabalho
seja incluído nas equipes multiprofissionais de
Segurança e Medicina do Trabalho, exatamente pela
característica do seu fazer, uma vez que este possui
habilidades gerenciais e psicossociais ligadas à
produção de saúde. Ele, dentro das ações nesta área,
buscará desenvolver planos estratégicos que tornem
as organizações mais saudáveis, integrando os
trabalhadores em prol do crescimento coletivo
organizacional, de maneira prática e reflexiva sobre o
desenvolvimento dos processos de trabalho, não
mais individual. Promovendo, assim, medidas que
coíbam de forma efetiva a prática do assédio moral
laboral22.

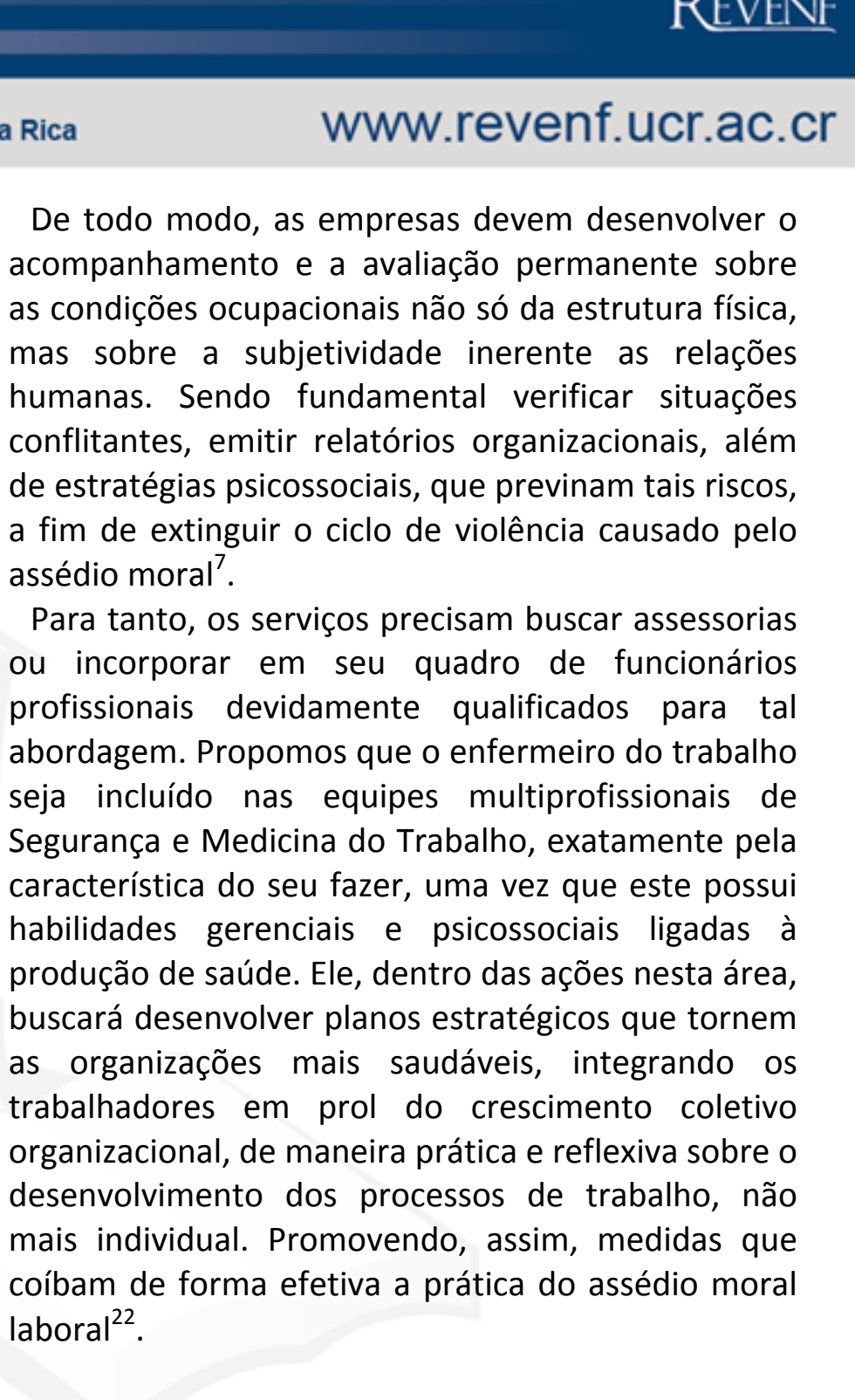 \\ WWW.revenf.UCr.aC.Cr
De todo modo, as empresas devem desenvolver o
acompanhamento e a avaliação permanente sobre
as condições ocupacionais não só da estrutura física,
mas sobre a subjetividade inerente as relações
humanas. Sendo fundamental verificar situações
conflitantes, emitir relatórios organizacionais, além
de estratégias psicossociais, que previnam tais riscos,
a fim de extinguir o ciclo de violência causado pelo
assédio moral?.
Para tanto, os serviços precisam buscar assessorias
ou incorporar em seu quadro de funcionários
profissionais devidamente qualificados para tal
abordagem. Propomos que o enfermeiro do trabalho
seja incluído nas equipes multiprofissionais de
Segurança e Medicina do Trabalho, exatamente pela
característica do seu fazer, uma vez que este possui
habilidades gerenciais e psicossociais ligadas à
produção de saúde. Ele, dentro das ações nesta área,
buscará desenvolver planos estratégicos que tornem
as organizações mais saudáveis, integrando os
trabalhadores em prol do crescimento coletivo
organizacional, de maneira prática e reflexiva sobre o
desenvolvimento dos processos de trabalho, não
mais individual. Promovendo, assim, medidas que
coíbam de forma efetiva a prática do assédio moral
laboral22. \\ WWW.revenf. UCr.aC.Cr
De todo modo, as empresas devem desenvolver o
acompanhamento e a avaliação permanente sobre
as condições ocupacionais não só da estrutura física,
mas sobre a subjetividade inerente as relações
humanas. Sendo fundamental verificar situações
conflitantes, emitir relatórios organizacionais, além
de estratégias psicossociais, que previnam tais riscos,
a fim de extinguir o ciclo de violência causado pelo
assédio moral?
Para tanto, os serviços precisam buscar assessorias
ou incorporar em seu quadro de funcionários
profissionais devidamente qualificados para tal
abordagem. Propomos que o enfermeiro do trabalho
seja incluído nas equipes multiprofissionais de
Segurança e Medicina do Trabalho, exatamente pela
característica do seu fazer, uma vez que este possui
habilidades gerenciais e psicossociais ligadas à
produção de saúde. Ele, dentro das ações nesta área,
buscará desenvolver planos estratégicos que tornem
as organizações mais saudáveis, integrando os
trabalhadores em prol do crescimento coletivo
organizacional, de maneira prática e reflexiva sobre o
desenvolvimento dos processos de trabalho, não
mais individual. Promovendo, assim, medidas que
coíbam de forma efetiva a prática do assédio moral
laboral22.

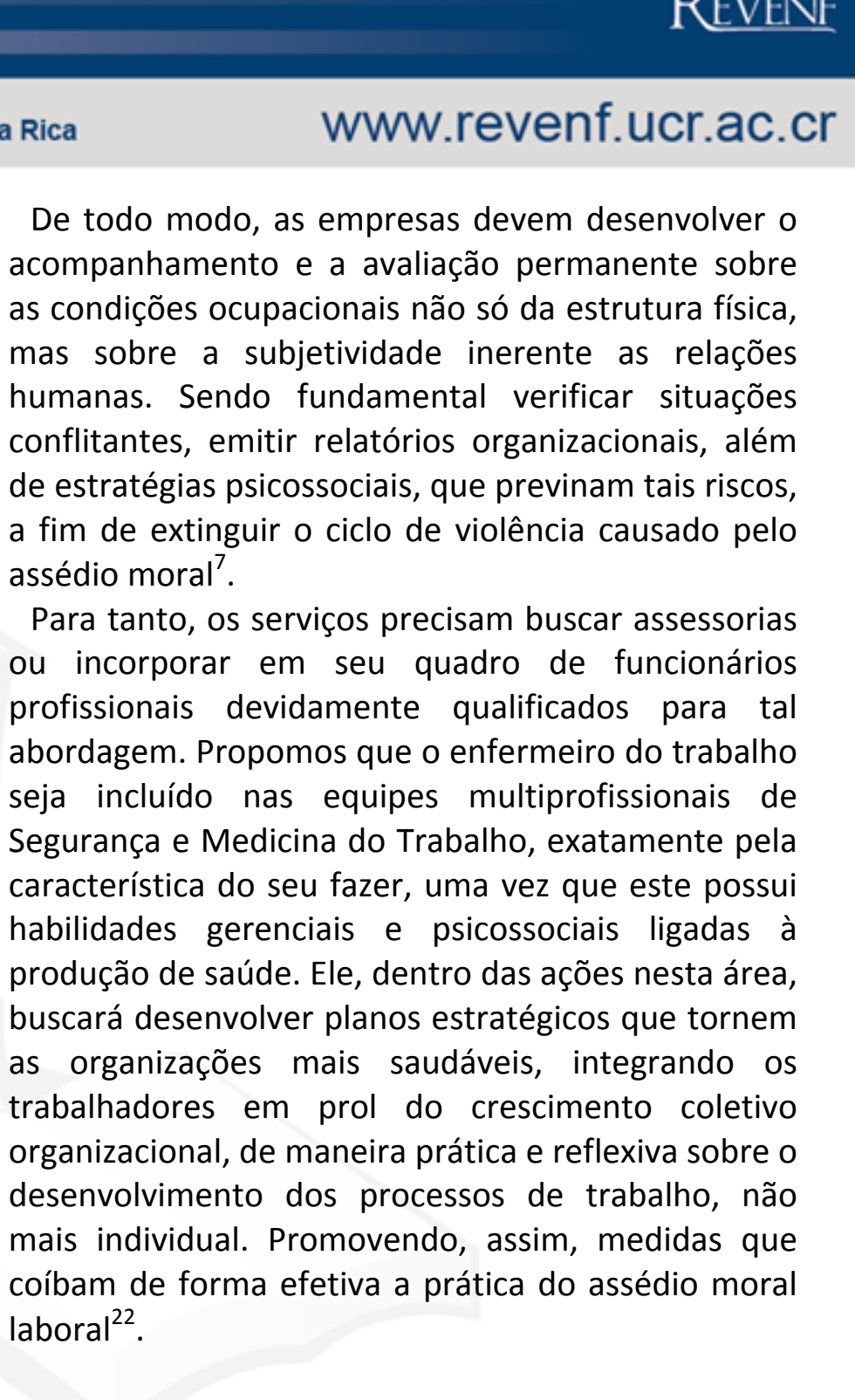 \\ WWW.revenf. UCr.aC.Cr
De todo modo, as empresas devem desenvolver o
acompanhamento e a avaliação permanente sobre
as condições ocupacionais não só da estrutura física,
mas sobre a subjetividade inerente as relações
humanas. Sendo fundamental verificar situações
conflitantes, emitir relatórios organizacionais, além
de estratégias psicossociais, que previnam tais riscos,
a fim de extinguir o ciclo de violência causado pelo
assédio moral?
Para tanto, os serviços precisam buscar assessorias
ou incorporar em seu quadro de funcionários
profissionais devidamente qualificados para tal
abordagem. Propomos que o enfermeiro do trabalho
seja incluído nas equipes multiprofissionais de
Segurança e Medicina do Trabalho, exatamente pela
característica do seu fazer, uma vez que este possui
habilidades gerenciais e psicossociais ligadas à
produção de saúde. Ele, dentro das ações nesta área,
buscará desenvolver planos estratégicos que tornem
as organizações mais saudáveis, integrando os
trabalhadores em prol do crescimento coletivo
organizacional, de maneira prática e reflexiva sobre o
desenvolvimento dos processos de trabalho, não
mais individual. Promovendo, assim, medidas que
coíbam de forma efetiva a prática do assédio moral
laboral22. \\ WWW.revenf.UCr.ac. Cr
Rica
De todo modo, as empresas devem desenvolver o
acompanhamento e a avaliação permanente sobre
as condições ocupacionais não só da estrutura física,
mas sobre a subjetividade inerente as relações
humanas. Sendo fundamental verificar situações
conflitantes, emitir relatórios organizacionais, além
de estratégias psicossociais, que previnam tais riscos,
a fim de extinguir o ciclo de violência causado pelo
assédio moral'.
Para tanto, os serviços precisam buscar assessorias
ou incorporar em seu quadro de funcionários
profissionais devidamente qualificados para tal
abordagem. Propomos que o enfermeiro do trabalho
seja incluído nas equipes multiprofissionais de
Segurança e Medicina do Trabalho, exatamente pela
característica do seu fazer, uma vez que este possui
habilidades gerenciais e psicossociais ligadas à
produção de saúde. Ele, dentro das ações nesta área,
buscará desenvolver planos estratégicos que tornem
as organizações mais saudáveis, integrando os
trabalhadores em prol do crescimento coletivo
organizacional, de maneira prática e reflexiva sobre o
desenvolvimento dos processos de trabalho, não
mais individual. Promovendo, assim, medidas que
coíbam de forma efetiva a prática do assédio moral
laboral22.

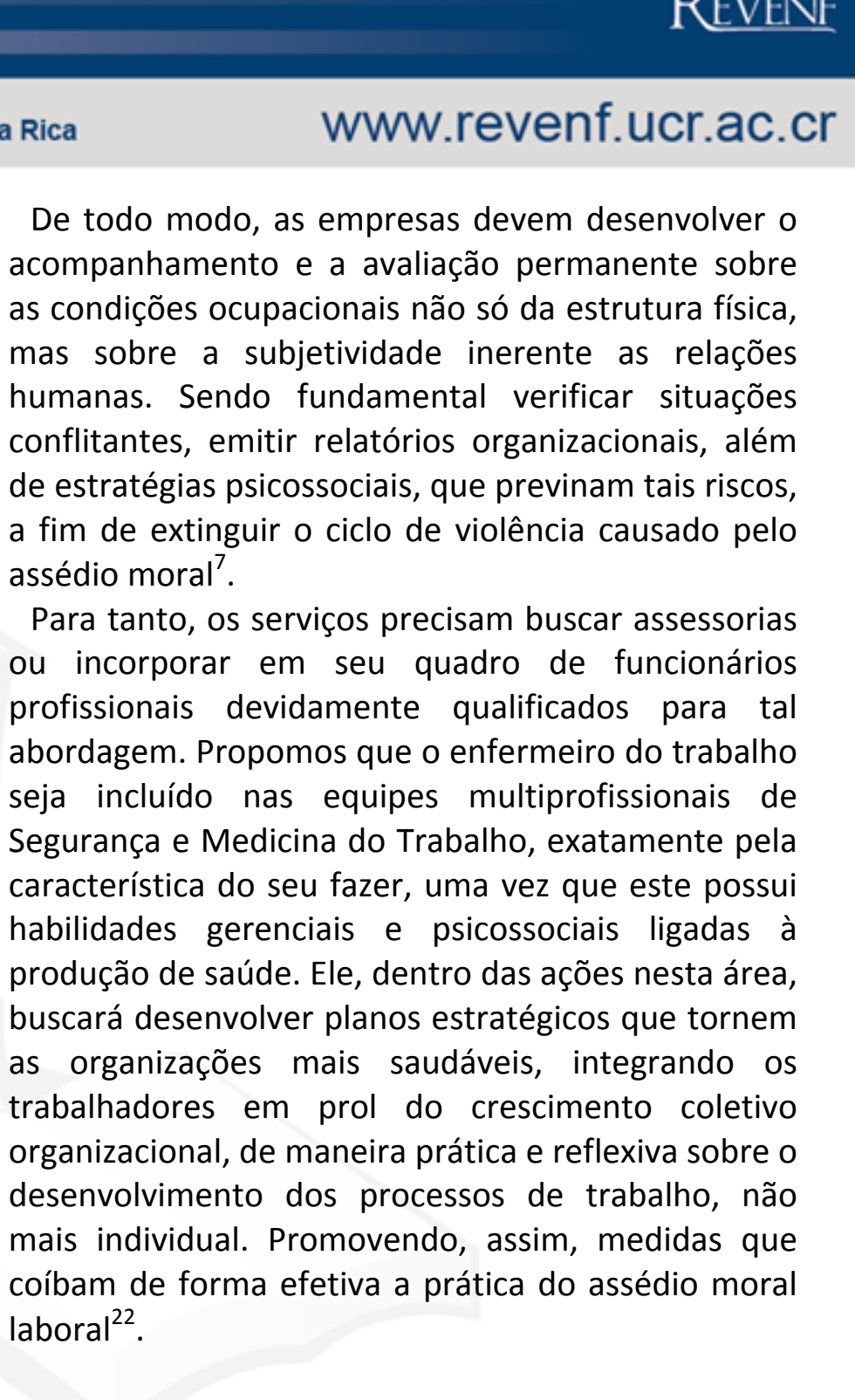 \\ WWW.revenf. UCr.aC. Cr
Re todo modo, as empresas devem desenvolver o
acompanhamento e a avaliação permanente sobre
as condições ocupacionais não só da estrutura física,
mas sobre a subjetividade inerente as relações
humanas. Sendo fundamental verificar situações
conflitantes, emitir relatórios organizacionais, além
de estratégias psicossociais, que previnam tais riscos,
a fim de extinguir o ciclo de violência causado pelo
assédio moral7
Para tanto, os serviços precisam buscar assessorias
ou incorporar em seu quadro de funcionários
profissionais devidamente qualificados para tal
abordagem. Propomos que o enfermeiro do trabalho
seja incluído nas equipes multiprofissionais de
Segurança e Medicina do Trabalho, exatamente pela
característica do seu fazer, uma vez que este possui
habilidades gerenciais e psicossociais ligadas à
produção de saúde. Ele, dentro das ações nesta área,
buscará desenvolver planos estratégicos que tornem
as organizações mais saudáveis, integrando os
trabalhadores em prol do crescimento coletivo
organizacional, de maneira prática e reflexiva sobre o
desenvolvimento dos processos de trabalho, não
mais individual. Promovendo, assim, medidas que
coíbam de forma efetiva a prática do assédio moral
laboral22. \\ WWW.revenf. UCr.aC.Cr
De todo modo, as empresas devem desenvolver o
acompanhamento e a avaliação permanente sobre
as condições ocupacionais não só da estrutura física,
mas sobre a subjetividade inerente as relações
humanas. Sendo fundamental verificar situações
conflitantes, emitir relatórios organizacionais, além
de estratégias psicossociais, que previnam tais riscos,
a fim de extinguir o ciclo de violência causado pelo
assédio moral?
Para tanto, os serviços precisam buscar assessorias
ou incorporar em seu quadro de funcionários
profissionais devidamente qualificados para tal
abordagem. Propomos que o enfermeiro do trabalho
seja incluído nas equipes multiprofissionais de
Segurança e Medicina do Trabalho, exatamente pela
característica do seu fazer, uma vez que este possui
habilidades gerenciais e psicossociais ligadas à
produção de saúde. Ele, dentro das ações nesta área,
buscará desenvolver planos estratégicos que tornem
as organizações mais saudáveis, integrando os
trabalhadores em prol do crescimento coletivo
organizacional, de maneira prática e reflexiva sobre o
desenvolvimento dos processos de trabalho, não
mais individual. Promovendo, assim, medidas que
coíbam de forma efetiva a prática do assédio moral
laboral22.

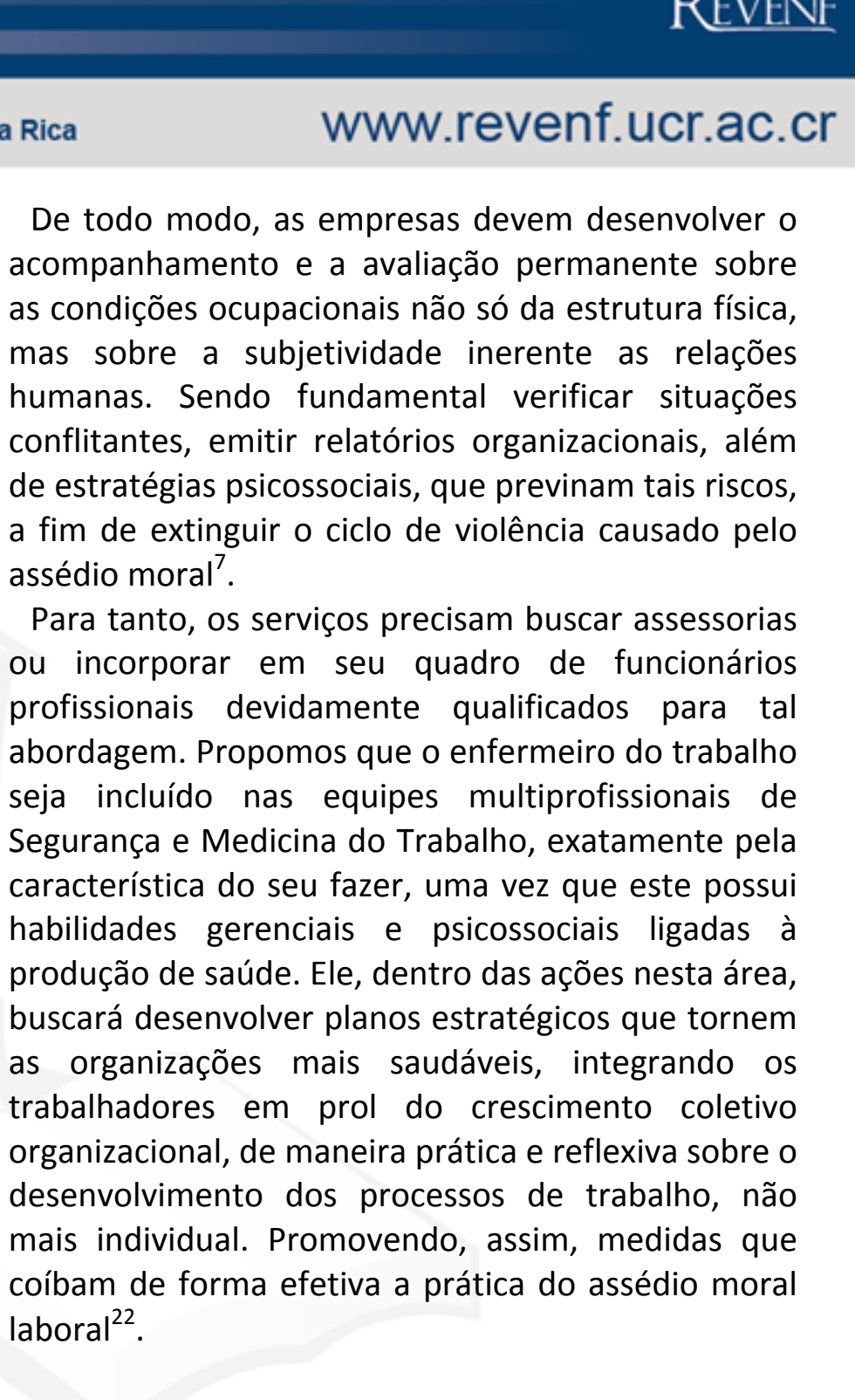 \\ WWW.revenf.UCr.aC.Cr
De todo modo, as empresas devem desenvolver o
acompanhamento e a avaliação permanente sobre
as condições ocupacionais não só da estrutura física,
mas sobre a subjetividade inerente as relações
humanas. Sendo fundamental verificar situações
conflitantes, emitir relatórios organizacionais, além
de estratégias psicossociais, que previnam tais riscos,
a fim de extinguir o ciclo de violência causado pelo
assédio moral?.
Para tanto, os serviços precisam buscar assessorias
ou incorporar em seu quadro de funcionários
profissionais devidamente qualificados para tal
abordagem. Propomos que o enfermeiro do trabalho
seja incluído nas equipes multiprofissionais de
Segurança e Medicina do Trabalho, exatamente pela
característica do seu fazer, uma vez que este possui
habilidades gerenciais e psicossociais ligadas à
produção de saúde. Ele, dentro das ações nesta área,
buscará desenvolver planos estratégicos que tornem
as organizações mais saudáveis, integrando os
trabalhadores em prol do crescimento coletivo
organizacional, de maneira prática e reflexiva sobre o
desenvolvimento dos processos de trabalho, não
mais individual. Promovendo, assim, medidas que
coíbam de forma efetiva a prática do assédio moral
laboral22. \\ WWW.revenf. UCr.aC. Cr
Re todo modo, as empresas devem desenvolver o
acompanhamento e a avaliação permanente sobre
as condições ocupacionais não só da estrutura física,
mas sobre a subjetividade inerente as relações
humanas. Sendo fundamental verificar situações
conflitantes, emitir relatórios organizacionais, além
de estratégias psicossociais, que previnam tais riscos,
a fim de extinguir o ciclo de violência causado pelo
assédio moral7
Para tanto, os serviços precisam buscar assessorias
ou incorporar em seu quadro de funcionários
profissionais devidamente qualificados para tal
abordagem. Propomos que o enfermeiro do trabalho
seja incluído nas equipes multiprofissionais de
Segurança e Medicina do Trabalho, exatamente pela
característica do seu fazer, uma vez que este possui
habilidades gerenciais e psicossociais ligadas à
produção de saúde. Ele, dentro das ações nesta área,
buscará desenvolver planos estratégicos que tornem
as organizações mais saudáveis, integrando os
trabalhadores em prol do crescimento coletivo
organizacional, de maneira prática e reflexiva sobre o
desenvolvimento dos processos de trabalho, não
mais individual. Promovendo, assim, medidas que
coíbam de forma efetiva a prática do assédio moral
laboral22. \\ WWW.revenf. UCr.aC. Cr
Re todo modo, as empresas devem desenvolver o
acompanhamento e a avaliação permanente sobre
as condições ocupacionais não só da estrutura física,
mas sobre a subjetividade inerente as relações
humanas. Sendo fundamental verificar situações
conflitantes, emitir relatórios organizacionais, além
de estratégias psicossociais, que previnam tais riscos,
a fim de extinguir o ciclo de violência causado pelo
assédio moral7
Para tanto, os serviços precisam buscar assessorias
ou incorporar em seu quadro de funcionários
profissionais devidamente qualificados para tal
abordagem. Propomos que o enfermeiro do trabalho
seja incluído nas equipes multiprofissionais de
Segurança e Medicina do Trabalho, exatamente pela
característica do seu fazer, uma vez que este possui
habilidades gerenciais e psicossociais ligadas à
produção de saúde. Ele, dentro das ações nesta área,
buscará desenvolver planos estratégicos que tornem
as organizações mais saudáveis, integrando os
trabalhadores em prol do crescimento coletivo
organizacional, de maneira prática e reflexiva sobre o
desenvolvimento dos processos de trabalho, não
mais individual. Promovendo, assim, medidas que
coíbam de forma efetiva a prática do assédio moral
laboral22. \\ WWW.revenf. UCr.aC.Cr
De todo modo, as empresas devem desenvolver o
acompanhamento e a avaliação permanente sobre
as condições ocupacionais não só da estrutura física,
mas sobre a subjetividade inerente as relações
humanas. Sendo fundamental verificar situações
conflitantes, emitir relatórios organizacionais, além
de estratégias psicossociais, que previnam tais riscos,
a fim de extinguir o ciclo de violência causado pelo
assédio moral?
Para tanto, os serviços precisam buscar assessorias
ou incorporar em seu quadro de funcionários
profissionais devidamente qualificados para tal
abordagem. Propomos que o enfermeiro do trabalho
seja incluído nas equipes multiprofissionais de
Segurança e Medicina do Trabalho, exatamente pela
característica do seu fazer, uma vez que este possui
habilidades gerenciais e psicossociais ligadas à
produção de saúde. Ele, dentro das ações nesta área,
buscará desenvolver planos estratégicos que tornem
as organizações mais saudáveis, integrando os
trabalhadores em prol do crescimento coletivo
organizacional, de maneira prática e reflexiva sobre o
desenvolvimento dos processos de trabalho, não
mais individual. Promovendo, assim, medidas que
coíbam de forma efetiva a prática do assédio moral
laboral22. \\ WWW.revenf. UCr.aC.Cr
De todo modo, as empresas devem desenvolver o
acompanhamento e a avaliação permanente sobre
as condições ocupacionais não só da estrutura física,
mas sobre a subjetividade inerente as relações
humanas. Sendo fundamental verificar situações
conflitantes, emitir relatórios organizacionais, além
de estratégias psicossociais, que previnam tais riscos,
a fim de extinguir o ciclo de violência causado pelo
assédio moral?
Para tanto, os serviços precisam buscar assessorias
ou incorporar em seu quadro de funcionários
profissionais devidamente qualificados para tal
abordagem. Propomos que o enfermeiro do trabalho
seja incluído nas equipes multiprofissionais de
Segurança e Medicina do Trabalho, exatamente pela
característica do seu fazer, uma vez que este possui
habilidades gerenciais e psicossociais ligadas à
produção de saúde. Ele, dentro das ações nesta área,
buscará desenvolver planos estratégicos que tornem
as organizações mais saudáveis, integrando os
trabalhadores em prol do crescimento coletivo
organizacional, de maneira prática e reflexiva sobre o
desenvolvimento dos processos de trabalho, não
mais individual. Promovendo, assim, medidas que
coíbam de forma efetiva a prática do assédio moral
laboral22. \\ WWW.revenf. UCr.aC. Cr
Re todo modo, as empresas devem desenvolver o
acompanhamento e a avaliação permanente sobre
as condições ocupacionais não só da estrutura física,
mas sobre a subjetividade inerente as relações
humanas. Sendo fundamental verificar situações
conflitantes, emitir relatórios organizacionais, além
de estratégias psicossociais, que previnam tais riscos,
a fim de extinguir o ciclo de violência causado pelo
assédio moral7
Para tanto, os serviços precisam buscar assessorias
ou incorporar em seu quadro de funcionários
profissionais devidamente qualificados para tal
abordagem. Propomos que o enfermeiro do trabalho
seja incluído nas equipes multiprofissionais de
Segurança e Medicina do Trabalho, exatamente pela
característica do seu fazer, uma vez que este possui
habilidades gerenciais e psicossociais ligadas à
produção de saúde. Ele, dentro das ações nesta área,
buscará desenvolver planos estratégicos que tornem
as organizações mais saudáveis, integrando os
trabalhadores em prol do crescimento coletivo
organizacional, de maneira prática e reflexiva sobre o
desenvolvimento dos processos de trabalho, não
mais individual. Promovendo, assim, medidas que
coíbam de forma efetiva a prática do assédio moral
laboral22. \\ WWW.revenf.UCr.aC.Cr
De todo modo, as empresas devem desenvolver o
acompanhamento e a avaliação permanente sobre
as condições ocupacionais não só da estrutura física,
mas sobre a subjetividade inerente as relações
humanas. Sendo fundamental verificar situações
conflitantes, emitir relatórios organizacionais, além
de estratégias psicossociais, que previnam tais riscos,
a fim de extinguir o ciclo de violência causado pelo
assédio moral?.
Para tanto, os serviços precisam buscar assessorias
ou incorporar em seu quadro de funcionários
profissionais devidamente qualificados para tal
abordagem. Propomos que o enfermeiro do trabalho
seja incluído nas equipes multiprofissionais de
Segurança e Medicina do Trabalho, exatamente pela
característica do seu fazer, uma vez que este possui
habilidades gerenciais e psicossociais ligadas à
produção de saúde. Ele, dentro das ações nesta área,
buscará desenvolver planos estratégicos que tornem
as organizações mais saudáveis, integrando os
trabalhadores em prol do crescimento coletivo
organizacional, de maneira prática e reflexiva sobre o
desenvolvimento dos processos de trabalho, não
mais individual. Promovendo, assim, medidas que
coíbam de forma efetiva a prática do assédio moral
laboral22. \\ WWW.revenf. UCr.aC.Cr
De todo modo, as empresas devem desenvolver o
acompanhamento e a avaliação permanente sobre
as condições ocupacionais não só da estrutura física,
mas sobre a subjetividade inerente as relações
humanas. Sendo fundamental verificar situações
conflitantes, emitir relatórios organizacionais, além
de estratégias psicossociais, que previnam tais riscos,
a fim de extinguir o ciclo de violência causado pelo
assédio moral?
Para tanto, os serviços precisam buscar assessorias
ou incorporar em seu quadro de funcionários
profissionais devidamente qualificados para tal
abordagem. Propomos que o enfermeiro do trabalho
seja incluído nas equipes multiprofissionais de
Segurança e Medicina do Trabalho, exatamente pela
característica do seu fazer, uma vez que este possui
habilidades gerenciais e psicossociais ligadas à
produção de saúde. Ele, dentro das ações nesta área,
buscará desenvolver planos estratégicos que tornem
as organizações mais saudáveis, integrando os
trabalhadores em prol do crescimento coletivo
organizacional, de maneira prática e reflexiva sobre o
desenvolvimento dos processos de trabalho, não
mais individual. Promovendo, assim, medidas que
coíbam de forma efetiva a prática do assédio moral
laboral22. \\ WWW.revenf. UCr.aC. Cr
Re todo modo, as empresas devem desenvolver o
acompanhamento e a avaliação permanente sobre
as condições ocupacionais não só da estrutura física,
mas sobre a subjetividade inerente as relações
humanas. Sendo fundamental verificar situações
conflitantes, emitir relatórios organizacionais, além
de estratégias psicossociais, que previnam tais riscos,
a fim de extinguir o ciclo de violência causado pelo
assédio moral7
Para tanto, os serviços precisam buscar assessorias
ou incorporar em seu quadro de funcionários
profissionais devidamente qualificados para tal
abordagem. Propomos que o enfermeiro do trabalho
seja incluído nas equipes multiprofissionais de
Segurança e Medicina do Trabalho, exatamente pela
característica do seu fazer, uma vez que este possui
habilidades gerenciais e psicossociais ligadas à
produção de saúde. Ele, dentro das ações nesta área,
buscará desenvolver planos estratégicos que tornem
as organizações mais saudáveis, integrando os
trabalhadores em prol do crescimento coletivo
organizacional, de maneira prática e reflexiva sobre o
desenvolvimento dos processos de trabalho, não
mais individual. Promovendo, assim, medidas que
coíbam de forma efetiva a prática do assédio moral
laboral22. \\ WWW.revenf. UCr.aC.Cr
De todo modo, as empresas devem desenvolver o
acompanhamento e a avaliação permanente sobre
as condições ocupacionais não só da estrutura física,
mas sobre a subjetividade inerente as relações
humanas. Sendo fundamental verificar situações
conflitantes, emitir relatórios organizacionais, além
de estratégias psicossociais, que previnam tais riscos,
a fim de extinguir o ciclo de violência causado pelo
assédio moral?
Para tanto, os serviços precisam buscar assessorias
ou incorporar em seu quadro de funcionários
profissionais devidamente qualificados para tal
abordagem. Propomos que o enfermeiro do trabalho
seja incluído nas equipes multiprofissionais de
Segurança e Medicina do Trabalho, exatamente pela
característica do seu fazer, uma vez que este possui
habilidades gerenciais e psicossociais ligadas à
produção de saúde. Ele, dentro das ações nesta área,
buscará desenvolver planos estratégicos que tornem
as organizações mais saudáveis, integrando os
trabalhadores em prol do crescimento coletivo
organizacional, de maneira prática e reflexiva sobre o
desenvolvimento dos processos de trabalho, não
mais individual. Promovendo, assim, medidas que
coíbam de forma efetiva a prática do assédio moral
laboral22. \\ WWW.revenf. UCr.aC. Cr
Re todo modo, as empresas devem desenvolver o
acompanhamento e a avaliação permanente sobre
as condições ocupacionais não só da estrutura física,
mas sobre a subjetividade inerente as relações
humanas. Sendo fundamental verificar situações
conflitantes, emitir relatórios organizacionais, além
de estratégias psicossociais, que previnam tais riscos,
a fim de extinguir o ciclo de violência causado pelo
assédio moral7
Para tanto, os serviços precisam buscar assessorias
ou incorporar em seu quadro de funcionários
profissionais devidamente qualificados para tal
abordagem. Propomos que o enfermeiro do trabalho
seja incluído nas equipes multiprofissionais de
Segurança e Medicina do Trabalho, exatamente pela
característica do seu fazer, uma vez que este possui
habilidades gerenciais e psicossociais ligadas à
produção de saúde. Ele, dentro das ações nesta área,
buscará desenvolver planos estratégicos que tornem
as organizações mais saudáveis, integrando os
trabalhadores em prol do crescimento coletivo
organizacional, de maneira prática e reflexiva sobre o
desenvolvimento dos processos de trabalho, não
mais individual. Promovendo, assim, medidas que
coíbam de forma efetiva a prática do assédio moral
laboral22.

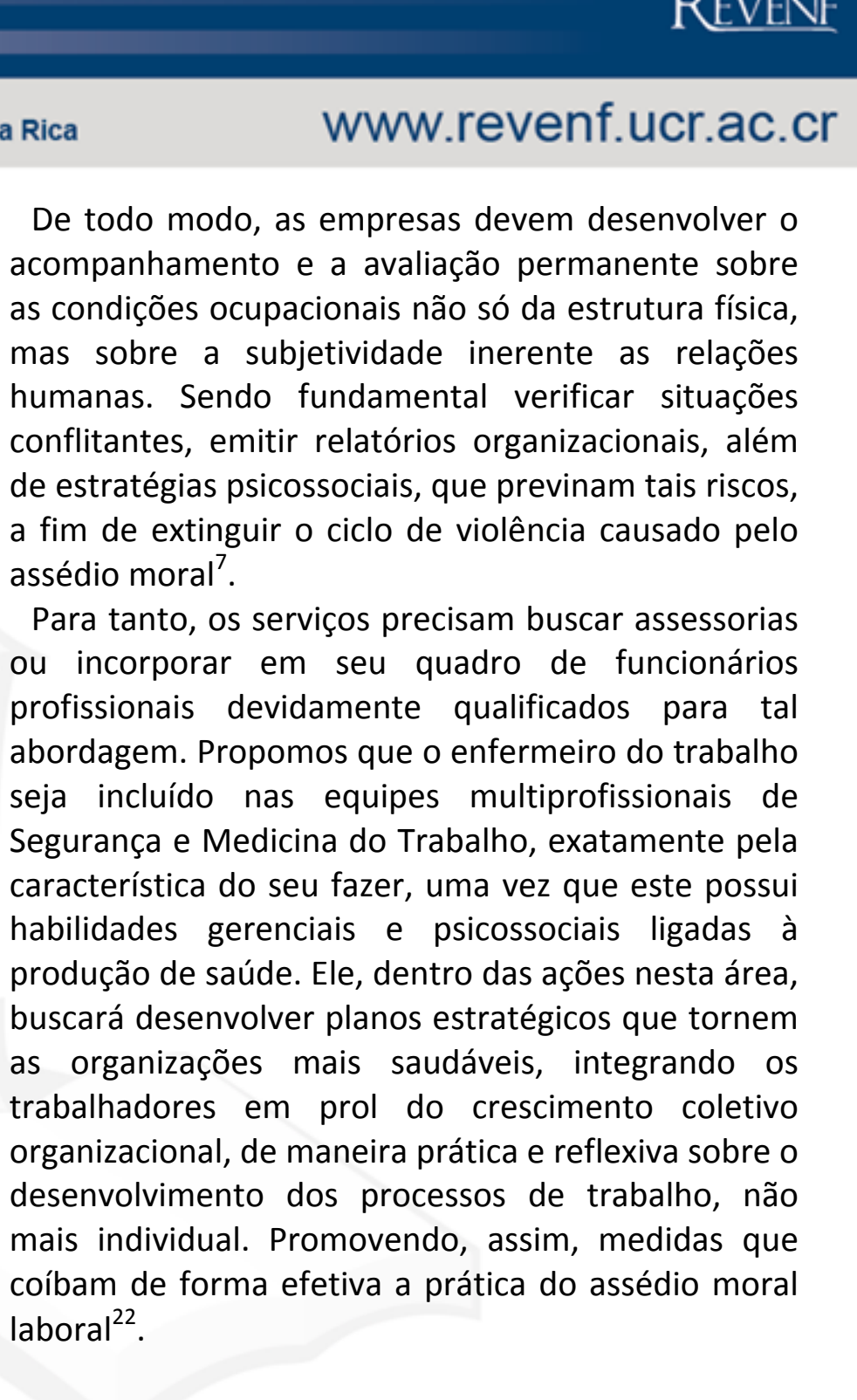

\section{ač̃os a parir da enfermagem do trabalho ações a partir da enfermagem do trabalho}

O contexto de atuação do enfermeiro do trabalho vem se reinventando a partir das transformações promovidas pelo mercado em busca do capital, em um processo de globalização das economias e do desenvolvimento de novas tecnologias. Com isso, a enfermagem do trabalho passa a lidar com cenários que envolvem o adoecimento do trabalhador, provocado pela precarização do trabalho, diante de ambientes que propiciam o assédio moral, como já discutido no texto anterior. 


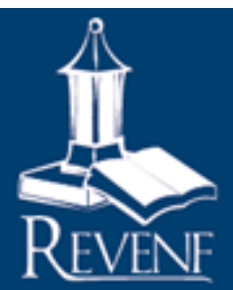

\section{Revista Electrónica Enfermeria Actual en costa Rica}

Neste ínterim, o enfermeiro do trabalho deve buscar desenvolver suas atividades com ênfase nas diretrizes da Política Nacional de Saúde do Trabalhador e da Trabalhadora brasileira, que tem como base a universalidade, integralidade e equidade, as quais dão base para as ações que favoreçam a participação da comunidade, dos trabalhadores e do controle social, os quais viabilizam a descentralização ${ }^{23}$ da tomada de decisão para a assistência direta aos trabalhadores, na gestão, supervisão, educação e promoção da saúde ocupacional, junto dos demais membros dos Serviços de Segurança e Medicina do Trabalho, como médico, psicólogo, terapeuta ocupacional, entre outros ${ }^{12}$.

Propõe-se, com base nas reflexões desenvolvidas a partir deste ensaio teórico, que o primeiro elemento de análise deve partir do diagnóstico psicossocial (Figura 2), o qual deve ser estruturado em dois momentos: a avaliação da cultura organizacional; e a identificação dos problemas dos trabalhadores.

A avaliação organizacional sobre o assédio moral parte dos nós críticos que envolvem a organização, enquanto campo de disputas de poder que pode favorecer a violência psicológica, a partir das políticas de gestão que orientam os processos de trabalho e produção ${ }^{6-10}$. Para tanto, o enfermeiro do trabalho deve estruturar sua análise a partir de quatro elementos, a saber: o reconhecimento da cultura organizacional, o diálogo com gestores, o reconhecimento do perfil de liderança e a avaliação da cultura organizacional.

\section{Figura 2}

Planejamento estratégico contra o ciclo de violência causado pelo assédio moral- Fortaleza, CE, 2020.

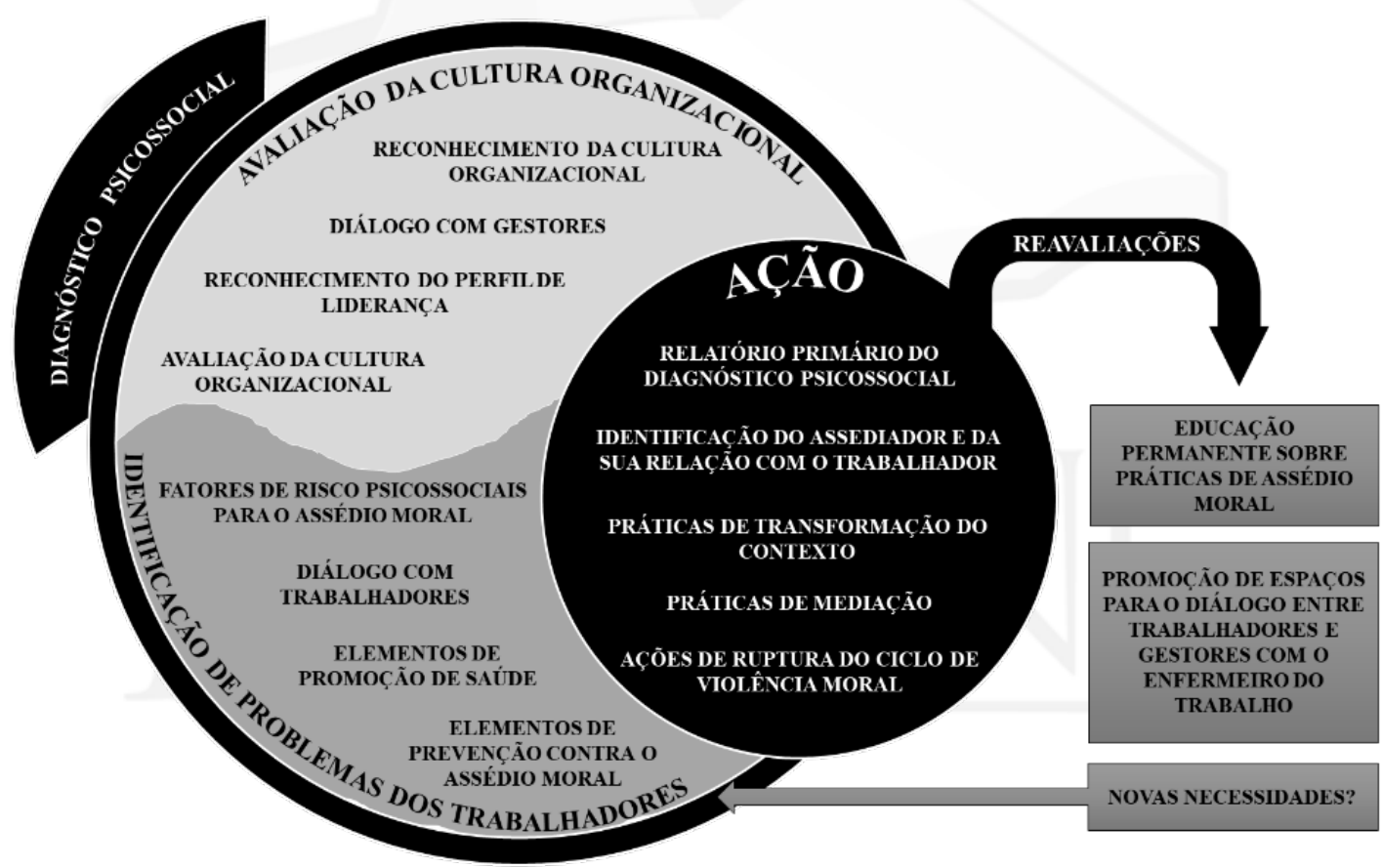

Fonte: Elaboração própria. 
Torna-se fundamental, em primeiro lugar, que tanto o enfermeiro do trabalho, como os demais membros da equipe multiprofissional de Segurança e Medicina do Trabalho reconheçam a cultura da organização, a partir das políticas instituídas, sua estrutura organizacional, seus objetivos e metas ${ }^{6,7,18}$. É a partir desse reconhecimento que o diálogo com os gestores deve ser desenvolvido, para que sua visão diante dos processos de trabalho e produção, seja compreendida, refletida e contextualizada ${ }^{2,7,9,10,19}$.

O reconhecimento do perfil de liderança, se autocrático, democrático ou liberal, é outro ponto chave, pois é a partir desta identificação que o enfermeiro do trabalho poderá compreender a forma como as relações de poder se estabelecem, a partir do comportamento do gestor ${ }^{4,12,19}$.

É somente após esse reconhecimento que a avaliação da cultura organizacional poderá ser compreendida, diante de suas implicações para a saúde e segurança ocupacional de seus trabalhadores, no que tange ser um ambiente propício ou não para o desenvolvimento de comportamentos que podem ser característicos do assédio moral ${ }^{2,7,10}$.

Já a identificação dos problemas dos trabalhadores busca compreender e contextualizar os aspectos de adoecimento psicossocial ligados ao trabalho, diante da divisão de tarefas, do respeito entre colaboradores e gestores, equidade dos processos avaliativos e da sobrecarga de trabalho ${ }^{7}$.

Este núcleo avaliativo, como apresentado na figura 2, é composto por quatro elementos: os fatores de risco psicossociais para o assédio moral; o diálogo com trabalhadores; os elementos de promoção da saúde; e os elementos de prevenção contra o assédio moral. Salienta-se que o processo de investigação e reconhecimento destes fatores de risco psicossociais é uma atividade complexa, diante da subjetividade do fenômeno ${ }^{7,9,13}$.
Logo, o enfermeiro do trabalho, deve buscar, antes de tudo, compreender que a transversalidade e multidimensionalidade sobre os determinantes da violência em decorrência do trabalho é uma constante, daí a dificuldade sobre a identificação, avaliação e quebra do ciclo de violência, pois ela é um fenômeno sistêmico, composto por aspectos micro e macro político e social, os quais correspondem as relações cotidianas do vir a ser, do interrelaciona-se, da relação dos trabalhadores com - mercado de trabalho e de suas formas de organização, cada vez mais precárias ${ }^{24}$.

Ao considerar a complexidade deste fenômeno, sugere-se a utilização do instrumento Leymann Inventory of Psychological Terror (LIPT) e de suas versões adaptadas e validadas para o contexto de cada país, o qual pode auxiliar o enfermeiro do trabalho na identificação e análise instrumental, sobre os aspectos psicossociais da violência no trabalho, por meio do reconhecimento de situações de assédio moral, físico e psicológico, os quais produzem descrédito e desprestígio ao trabalhador, envolvendo distorção de comunicação entre boatos, injúria, comparação pejorativa entre trabalhadores, além da minimização de suas necessidades ou do seu fazer $^{25}$.

Logo, os dados gerados pelo LIPT, podem ser contextualizados e endossados pelo ciclo de Planejamento Estratégico contra o ciclo de violência causado pelo assédio moral, para que o enfermeiro do trabalho consiga buscar soluções com maior amplitude sobre a problemática.

Portanto é preciso que este profissional tenha a sensibilidade no olhar para que as relações de poder, enquanto promotoras de danos à saúde dos trabalhadores, possam ser identificadas por meio da observação dos atos não ditos. O enfermeiro do trabalho deve considerar que o assédio moral, pode ser praticado dentro ou fora do serviço ou em 
ambientes virtuais, por meio de mensagens em aplicativos de smartphones.

Desta forma, toda e qualquer ação percebida ou informada sobre imposição de poder que leve a comportamentos de humilhação, hostilização, desprezo, ofensas e constrangimento deve ser registrada e analisada ${ }^{7,10,20}$.

Reitera-se que o diálogo com os trabalhadores pode ocorrer junto à fase de identificação dos riscos psicossociais. É por meio do diálogo que o enfermeiro do trabalho passará a compreender a realidade vivida por estes ${ }^{2,22}$. Deve-se promover um espaço de conversação acolhedor, seguro e terapêutico diante da identificação do problema e de sua resolução.

Compreende-se a partir disso, que há fatores objetivos, como a dinâmica do serviço, que inferem diretamente na carga horária a ser cumprida, além dos elementos subjetivos que envolvem o interesse dos gestores e dos próprios profissionais em dinamizar esses espaços ${ }^{6,7,9,12}$.

Para tanto, o enfermeiro do trabalho pode lançar mão de estratégias que viabilizem o desenvolvimento desses meios, de modo individual e/ou coletivo. No atendimento individual e/ou no encontro semanal em local reservado, sem que ocorra a interferência de terceiros. Onde este profissional possa acolher por meio da escuta as necessidades dos trabalhadores, para que uma tomada de conduta seja desenvolvida ${ }^{2,7,12}$.

Já os elementos de promoção e prevenção da saúde, relacionados à educação permanente, são espaços de diálogos e escuta, que fazem parte das ações setoriais e organizacionais que podem ou não existir em uma empresa, sendo fundamental que o enfermeiro do trabalho reconheça ou não sua existência e adequabilidade frente às necessidades dos trabalhadores, diante das exigências promovidas pela organização ${ }^{7,12}$.
Outrossim, propõe-se que os elementos citados nas etapas de avaliação psicossocial sejam registrados, organizados, categorizados e analisados pelo enfermeiro do trabalho em relatório específico sobre a identificação e o combate do assédio moral no trabalho. Este relatório será o produto primário que dará base às ações de planejamento estratégico contra o ciclo de violência causado pelo assédio moral.

A construção do relatório primário a partir do diagnóstico psicossocial do serviço tem como potência a visão ampla da problemática, mapeando setores com possíveis riscos para o assédio moral, diante da representação da estrutura da organização junto a execução dos processos de trabalho ${ }^{7,12}$.

Portanto, é a partir deste documento que o enfermeiro do trabalho produzirá evidências sobre as condições de trabalho que influenciam a ocorrência do assédio moral, identificando o assediador e sua relação com o trabalhador ou grupo de trabalhadores. Assim, as proposições devem ser construídas com base no relatório primário, por meio da organização de uma comissão idônea que tenha como membros representantes dos trabalhadores, do serviço, além do enfermeiro do trabalho, que será agente gestor, supervisor e mediador das ações de combate ao assédio moral ${ }^{12}$.

Com este cenário estruturado, o enfermeiro do trabalho precisa refletir e discutir junto a essa comissão se existe ambiente propício que favoreça a reconstrução das práticas de transformação do contexto, até então favorável ao desenvolvimento do assédio moral.

Outro ponto elementar é o reconhecimento por parte do agressor, enquanto assediador, para que se possa potencializar a mudança de seu comportamento, por meio de tratamento psicológico ${ }^{9}$. Para que, assim, as relações possam ser reconstruídas com base no respeito mútuo. Salvo as situações em que o agressor não consiga mudar seu 
comportamento, por não compreender que os atos praticados por ele são caracterizados como assédio moral, ou por alegar ser a forma normal de lidar com as pessoas, devendo, portanto, ser advertido, transferido de setor, retirado da equipe ou afastado do serviço, para que se evite novos conflitos ${ }^{9,22}$.

Como em todo ciclo avaliativo, reitera-se a importância da reavaliação dos processos apresentados pela figura 2. Esta etapa é elementar, pois busca incentivar que as empresas criem dentro de sua estrutura organizacional um centro de ações voltadas para a prevenção dos riscos ocupacionais, por meio da educação permanente sobre práticas de assédio moral. $O$ que dará base para a promoção de espaços para o diálogo entre trabalhadores e gestores com o enfermeiro do trabalho, para o fortalecimento dos espaços coletivos de luta contra o assédio moral diante de novas necessidades que possam surgir.

\section{CONCLUSÕES}

A dinâmica do assédio moral no trabalho, perpassa questões de grande complexidade, sobretudo pela sua invisibilidade. No entanto, esse tipo de violência apresenta forte influência do tipo de modelo econômico adotado como políticas de Estado. Tendo isso em vista, a criticidade das reflexões feitas neste estudo, denotam o Neoberalismo, como principal modelo econômico que tende a segregar e a reprimir os trabalhadores, na tentativa de produzir cada vez mais, independente das condições ergonômicas e psicossociais.

Neste ínterim, entende-se que nos últimos anos, a constituição dos ambientes laborais é na sua maioria formado sob a lógica do trabalho precário, diante da perspectiva do neoliberalismo, sobre as formas de vínculos frágeis de emprego, demandas excessivas pela produção e a alienação sobre os direitos trabalhistas.
É a partir do reconhecimento desses aspectos e das dinâmicas organizacionais estabelecidas, que tanto o enfermeiro do trabalho, como os demais membros que compõe a equipe multiprofissional dos Serviços de Segurança e Medicina do Trabalho, identificarão as principais situações conflitantes características do assédio moral, seja pela organização ou trabalhador, independentemente do nível hierárquico.

Para tanto, é preciso que se faça um amplo diagnóstico por meio dos elementos sugeridos no Planejamento Estratégico Contra o Ciclo de Violência Moral, o qual considera os seguintes itens: avaliação da cultura organizacional; identificação dos problemas dos trabalhadores; ação (estratégias) e por fim, os processos de reavaliação permanente. Tais itens produzirão evidências sobre as condições de trabalho, identificando quem realiza e quem sofre o assédio moral, além de medidas a serem adotadas no campo organizacional, psicossocial e da promoção de práticas educativas contra este tipo de violência.

\section{CONFLITO DE INTERESSE}

os autores declaram não haver nenhum conflito de interesses.

\section{REFERÊNCIAS BIBLIOGRÁFICAS}

1. Marx K. O capital: crítica da economia política. O processo global da produção capitalista. São Paulo: Boitempo Editora; 2017.

2. Silva AKL, Marinho MID, Machado LSX, Queiroz JLF, Jucá RMN. Assédio moral no trabalho: do enfrentamento individual ao coletivo. Rev bras saúde ocup. 2019; $44 \quad$ (22):1-9. DOI:https://doi.org/10.1590/23176369000015918

3. Souza EA. Assédio moral e reforma trabalhista: entrevista com Margarida Barreto. Rev Katálysis. 2019; 22(3):641-51. DOI: 
https://doi.org/10.1590/1982-

$02592019 v 22 n 3 p 641$

4. Lucena PLC, Costa SFG, Batista JBV, Araújo ELM, Soares CCD, Rolim MGC. Testemunhas de assédio moral na Enfermagem: identificando características desse fenômeno, sentimentos e estratégias de enfrentamento. Rev Min Enferm. 2019; 23(1164):1-9. DOI: http://www.dx.doi.org/10.5935/1415-

2762.20190012

5. Cardoso ACM, Lima CR. A negociação coletiva e as possibilidades de intervenção nas situações de risco à saúde no trabalho. Rev bras saúde ocup. 2020;45(2):1-11.

DOI: https://doi.org/10.1590/2317-6369000004118

6. Barreto MMS. Assédio moral: a violência sutil. [Tese de Doutorado em Psicologia]. São Paulo: Pontifícia Universidade Católica de São Paulo- PUC SP.2005. Disponível em: https://tede2.pucsp.br/handle/handle/17370

7. Barreto MMS. Assédio moral: trabalho, doenças e morte. In:Anais de Seminário compreendendo o assédio moral no ambiente de trabalho, 2010; São Paulo: Fundacentro; 2013. p. 13-26. Disponível em:

http://www.assediomoral.ufsc.br/files/2013/03/S eminario-Combate-AMT-Fundacentro-2013.pdf

8. Soboll LAP. Assédio moral no trabalho. In: Cattani AD, Holzmann L. (Org.). Dicionário Crítico Tecnologia e Trabalho. Porto Alegre: UFRGS EDITORA; 2010. p. 40-6.

9. Soboll LA, Miara T, Moscalewaky J. A questão da intencionalidade no assédio moral. Trabalho (En) Cena. 2017; 2(2): 3-17, 2017. DOI: https://doi.org/10.20873/2526-1487V2N2P3

10.Glina DMR, Soboll L. A. Intervenções em assédio moral no trabalho: uma revisão da literatura. Rev bras saúde ocup. 2012;37(126): 269-83. DOI: https://doi.org/10.1590/S0303-

76572012000200008
11.Brasil. Ministério da Saúde, Organização PanAmericana Da Saúde. Doenças relacionadas ao trabalho: manual de procedimentos para os serviços de saúde. Brasília: Ministério da Saúde, OPAS; 2001. Disponível em: http://renastonline.ensp.fiocruz.br/recursos/doen cas-relacionadas-trabalho-manualprocedimentos-os-servicos-saude

12.Ribeiro MCS. Enfermagem do trabalho: fundamentos para a atenção à saúde dos trabalhadores. 2. ed. São Paulo: Martinari; 2012.

13.Pintor EAS, Garbin AC. Notificações de violência relacionadas ao trabalho e vigilância em saúde do trabalhador: rompendo a invisibilidade. Rev bras saúde ocup. 2019; 44(20):1-9. DOI: https://doi.org/10.1590/2317-6369000006918

14.Silva IV, Aquino MLE, Pinto ICM. Violência no trabalho em saúde: a experiência de servidores estaduais da saúde no Estado da Bahia, Brasil. Cad Saúde Pública. 2014; 30(10): 2112-22. DOI: https://doi.org/10.1590/0102-311X00146713

15.Antunes R, Praun L. A sociedade dos adoecimentos no trabalho. Serv Soc Soc. 2015;123:

DOI: https://doi.org/10.1590/0101-6628.030

16.Andrade CB,Assis SG.Assédio moral no trabalho, gênero, raça e poder: revisão de literatura. Rev bras saúde ocup. 2018; 43(11):1-13. DOI: $\quad$ https://doi.org/10.1590/23176369000012917

17.Barbosa AMS, Bender M. O reconhecimento jurídico das violências psicológicas nas relações de trabalho no Brasil. Caderno CRH. 2019; 32(86): 419-34.

DOI: https://doi.org/10.9771/ccrh.v32i86.20193

18.Souza TMS, Ducatti I. O enfrentamento do assédio moral pelos sindicatos: contribuições marxistas. Cad psicol soc trab. 2017; 20(1): 79-94. Disponível em: http://pepsic.bvsalud.org/scielo.php?script=sci_a 
bstract \&pid=S151637172017000100007\&lng=pt\& nrm=iso

19. Ribeiro VAB. Enfrentamento do assédio moral no trabalho: dimensões institucionais e aspecto subjetivo. Barbarói. 2018;51:193-211. DOI: http://dx.doi.org/10.17058/barbaroi.v51i1.6 236

20.Lucena PLC, Costa SFG, Batista JBV, Lucena CMF, Morais GSN, Costa BHS. Produção científica sobre assédio moral e enfermagem: estudo bibliométrico. Rev esc enferm USP.2018;52(03354):1-9. DOI: https://doi.org/10.1590/s1980-

220x2017029103354

21.Brasil. Presidência da República, Subchefia para Assuntos Jurídicos. Lei no 4.898, de 9 de dezembro de 1965.Regula o Direito de Representação e o processo de Responsabilidade Administrativa Civil e Penal, nos casos de abuso de autoridade. [Internet] Brasília, DF; 1965. Disponível em: http://www.planalto.gov.br/ccivil_03/leis//4898.h tm

22.Limoeiro DRP, Silva JLL, Coutinho GBF, Santos GL, França JVJ, Monteiro ET. Assédio moral como inimigo invisível no trabalho do enfermeiro. Rev Enferm Atenção Saúde. 2018;7(1):174-85. DOI: https://doi.org/10.18554/reas.v7i1.2392

23. Brasil. Ministério da Saúde. Portaria no 1.823, de 23 de agosto de 2012. Institui a Política Nacional de Saúde do Trabalhador e da Trabalhadora. Ministério da Saúde, Brasília; 2012. Disponível em: https://bvsms.saude.gov.br/bvs/saudelegis/gm/2 012/prt1823_23_08_2012.html

24.Toro JP, Gómez-Rubio C. Factores facilitadores de la violencia laboral: Una revisión de la evidencia científica en América Latina. Cienc Trab. 2016; 18(56): 110-116. DOI: http://dx.doi.org/10.4067/S071824492016000200006
25.Máximo C, Martins JS, Dominguez-Lara S, Lourenço A, Simões M. Adaptação e Análise da Estrutura Interna da Escala de Mobbing de Leymann (LIPT45) para o Contexto Português. Aval. psicol.2020; 19(1): 56-66. DOI: http://dx.doi.org/10.15689/ap.2020.1901.16105.0 7 